\title{
Influential Factors of VoIP Adoption of Top 500 Export-import Enterprises in Taiwan
}

\author{
Chun-Hsiung Liao \\ National Cheng Kung University \\ E-mail: chliao@mail.ncku.edu.tw \\ Po-Hsing Tseng \\ National Cheng Kung University \\ E-mail: icrt@mail.tcm.ncku.edu.tw
}

\begin{abstract}
Voice over Internet Protocol (VoIP) is a critical innovation technology in the globally oriented business world, which emphasizes flexibility and efficiency as means to reduce operation cost and improve service quality. Yet there is little research in the organization behavior literature investigating what factors affect enterprise decision to adopt VoIP. This study investigated significant determinants of VoIP adoption in the top 500 export-import enterprises in Taiwan. Logistic regression was used to examine four variables: top management support, environment competition, cost and business size. Specifically, the characteristic comparison of VoIP adopters and non-adopters were presented. We concluded by discussing weight ratio of VoIP adoption factor, characteristics of potential adopters and its managerial implications.
\end{abstract}

Keywords: VoIP, Adoption, Logistic Regression

\section{INTRODUCTION}

Voice over Internet Protocol (VoIP) is gaining ground among all types of telecommunications businesses in recent years. It is a technology started from 1995, for transmitting voice phone calls over data networks using Internet Protocol (IP). Government, educational and health institutions, as well as service-oriented financial and retailing corporations, were the early adopters of VoIP. With the advantage of VoIP, telephony signals are digitized via dedicated or shared circuits and are transmitted as packets to their destinations, just as with Internet/web call centers, 
e-commerce web messaging, chat rooms, e-learning, video streaming or any other kind of IP transaction (Tsai, 2006). VoIP comes in many forms nowadays. Some of them closely resemble traditional phone service from the point-of-view of end user. There are four types of connections providing VoIP, including IP to Public Switched Telephone Network (PSTN) through Internet (e.g., SkypeOut), IP to PSTN without Internet, IP to IP (e.g., MSN, Skype), and PSTN to PSTN (e.g., VoIP based on gateway, international valued direct call) (Shin, 2006).

Most enterprises' voice communications outside the enterprise network still travel over the PSTN. Tradition telephony with Private Branch eXchange (PBX), onsite at a telephone company office requires a leased analog line for each conversation. However, VoIP uses compression for more efficient use of bandwidth, enabling in principle a reduction in leased lines and simpler network management. VoIP also obviates the needs for a separate data and voice network, and hence, users can use the same line for browsing the Internet and phone calls. Businesses are benefiting from VoIP in more managed IP networks and intranets. In addition, they can put in a gateway to interface to an existing phone system or PBX, or replace a traditional device with an out-of-the-box IP PBX. With these types of deployments, businesses can avoid traditional telecommunications toll charges on calls, and distribute centralized PBX services to users in multiple locations across the managed IP network.

With rapid development of broadband network in recent years, wireless digital technology together with IP network provides a well opportunity for VoIP. Such evolution of information technology results in efficiencies that hold the potential for large-scale cost-effective replacement of existing enterprise network. These advantageous development tendencies bring unprecedented benefits to enterprise VoIP suppliers and user. According to Synergy Research (Wieder, 2006), revenues associated with enterprise VoIP all around the world topped $\$ 4$ billion in 2005, a 31 percent increase over 2004. Based on Market Intelligence Center1, the value of Taiwanese enterprise IP phone shipment was \$76 million in 2006 and the value of VoIP gateway shipment was predicted to be $\$ 12$ million in 2007. These amazing growths in enterprise VoIP revealed that this market is a potential researchable field in the telecommunications industry. In addition, VoIP is an innovation adoption technology which needs human and time investment, and thus, there are complicated factors in the adoption behavior of VoIP. These solutions for the above can provide valuable and meaningful information to suppliers in the VoIP market. Therefore, the

\footnotetext{
${ }^{1}$ http://mic.iii.org.tw
} 
purpose of this paper was to investigate VoIP's usage and users' characteristics of Top 500 Export-import Enterprises in Taiwan, and develop a model of influential factors to realize the key factors in the VoIP adoption.

The remainder of the paper is organized as follows. Next section provides literature review and develops hypotheses. In section 3, we report on the research methodology used in this study, including data collection and variable measurement. Section 4 summarized our discussion and conclusion.

\section{LITERATURE REVIEW}

For a business, VoIP is a technology innovation technique. Previous theoretical models of technology adoption revealed that a variety of factors may affect an organization's decision to adopt a particular technology (Rogers, 1983; Swanson, 1994). Know and Zmud (1987) reviewed prior innovation research and classified variables that potentially influence technology adoption into five broad categories: individual, task-related, innovation-related, organizational, and environmental characteristics. In this study, we are interested in enterprises' VoIP adoption, and thus the potential influential variables will be limited to organizational and environmental factors.

Many researches have revealed that the top management plays a critical role at an organization innovation adoption (Basu et al., 2002; Bradfort and Florin, 2003; Cerpa \& Verner, 1998; Grandon \& Pearson, 2004; Matta \& Moberg, 2006; Quaddus \& Xu, 2005; Steinbart \& Nath, 1992; Zhang et al., 2005). Mabert et al. (2006) found that senior executives were very involved throughout the enterprise resource planning (ERP) implementation, from the outset to completion, and also established clear priority. Jeyaraj et al. (2006) surveyed 51 studies on organizational information technology (IT) adoption published between 1992 and 2003 and found top management support was a positive impact on IT adoption. Those studies have examined that top management support could ensure adequate resources in the process of information adoption and create a supportive climate. Top management support was assessed by incorporating the three items: "increase the productivity", "employee easy to use" and "other companies have used," (see Jeyaraj et al., 2006; Premkumar and Roberts, 1999). These arguments lead to following hypothesis.

Hypothesis 1: There exists a positive relationship between top management support and adoption. 
Competitiveness of environment is a powerful predictor of innovation adoption for enterprises. Under the competing and rival pressure, they tend to be more responsive to and cautious about the actions of their competitors (Grandon \& Pearson, 2004; Jeyaraj et al., 2006; March \& Ngai, 2006; Premkumar \& Roberts, 1999). In oligopolies, the acceptance of technological innovations helps build or maintain barriers to entry and preserves cost advantage. Pressure from business partners and/or competitors has been found to be an important factor in electronic data interchange (EDI) adoption (Hart \& Saunders, 1998; Premkumar \& Ramamurthy, 1995). Export-import enterprise could build voice package link (due to nearly free network transmission) with their customers and partners to reduce operation cost and thereby be more competitive in the marketplace. Competitiveness of environment was assessed by including five items: "market share", "industry rivals", "market competitive pressure", "competitors have adopted" and "the influence of competitor's decision," (Grandon \& Pearson, 2004; Jeyaraj et al., 2006; Premkumar and Roberts, 1999). These arguments lead to following hypothesis.

Hypothesis 2: There exists a positive relationship between competitiveness of environment and adoption.

The related literature viewed cost as an important factor which influences innovation technology adoption (Lu et al., 2006; Mondragon et al., 2006; Premkumar et al., 1994; Rogers, 1983; Tornatzky \& Klein, 1982). The less expensive the innovation is, the more likely that it will be adopted. Premkumar and Roberts (1999) interviewed 78 enterprises and found that cost factor affects the adoption of new information technologies. Similarly, Tobin \& Bidoli (2006) found bandwidth cost was a barrier for firms to adopt VoIP in the South Africa. Those studies amply illustrated that cost is a significant deterrent to adopt new technology and therefore enterprise would evaluate the costs relative to the benefits before adopting innovation technology. The costs of adopting VoIP include component-initial investment cost, operation cost, and training cost. VoIP is an innovation technology that causes large-scale changes to the business communication methods. But significant costs may be incurred in the gateway deployment, network capacity, equipment upgrade, staffing and training costs. Cost was accessed by two items: "installation cost" and "maintenance cost" (Premkumar and Roberts, 1999). Therefore, cost may have a negative impact on the gradual adoption of VoIP systems. These arguments lead to following hypothesis.

Hypothesis 3: There is a negative relationship exists between cost and adoption. 
Business size has been the subject of scrutiny in many organization technology adoption studies (Lin, 1995; Matta \& Moberg, 2006; Patterson et al., 2003; Premkumar et al., 1997). It is theorized that larger organizations have the financial and technology resources to invest in new technologies and absorb the associated risk. (Dewar \& Dutton, 1986; Grover and Goslar, 1993). Camison-Zornoza et al. (2004) confirmed the existence of a significant and positive correlation between firm's size and innovation. Furthermore, it would appear reasonable to suppose that larger business have more potential to use information technology than small business does, simply because of their larger scale of operations. Cragg \& King (1993) showed that lack of technical knowledge and resource inhibits technology adoption in small firms. The case made here is that we could expect larger enterprises to have the resource and infrastructure to facilitate the adoption of VoIP. It is also due to the demand from their customers and partners. By doing so, they can reduce long-distance and international phone bill. Therefore, large enterprises could create greater efficiency of scale in VoIP application. Cost was assessed by including two items: "total revenue" and "number of employee" (Patterson et al., 2003). These arguments lead to following hypothesis. Table 1 summarizes the above literature on information technology adoption according to methodology and influencing factors.

Hypothesis 4: There exists a positive relationship between enterprise size and adoption.

Table 1 Summary of the literature on IT adoption

\begin{tabular}{llll}
\hline \multicolumn{1}{c}{ Source } & \multicolumn{1}{c}{ Studies } & Methodology & \multicolumn{1}{c}{ Influencing factors } \\
\hline $\begin{array}{l}\text { Jeyaraj et al. } \\
(2006)\end{array}$ & $\begin{array}{l}\text { IT innovation } \\
\text { adoption }\end{array}$ & $\begin{array}{l}\text { Qualitative } \\
\text { study }\end{array}$ & $\begin{array}{l}\text { Top management support, external } \\
\text { pressure, professionalism of the } \\
\text { information system unit, external } \\
\text { information sources. }\end{array}$ \\
\hline $\begin{array}{l}\text { March \& Ngai } \\
(2006)\end{array}$ & $\begin{array}{l}\text { Business to } \\
\text { Customer } \\
\text { e-commerce }\end{array}$ & $\begin{array}{l}\text { Logistic } \\
\text { regression }\end{array}$ & $\begin{array}{l}\text { Relative advantage, resource } \\
\text { competence, competition and partner } \\
\text { firm }\end{array}$ \\
\hline $\begin{array}{l}\text { Premkumar \& } \\
\text { Roberts (1999) }\end{array}$ & $\begin{array}{l}\text { Online data } \\
\text { access, e-mail, } \\
\text { and the Internet }\end{array}$ & $\begin{array}{l}\text { Discriminant } \\
\text { analysis }\end{array}$ & $\begin{array}{l}\text { Relative advantage, top management } \\
\text { support, organization size, external } \\
\text { competitive pressure }\end{array}$ \\
\hline $\begin{array}{l}\text { Tobin \& Bidoli } \\
(2006)\end{array}$ & $\begin{array}{l}\text { VoIP and other } \\
\text { converged IP }\end{array}$ & $\begin{array}{l}\text { Qualitative } \\
\text { study }\end{array}$ & $\begin{array}{l}\text { High bandwidth costs/high costs of } \\
\text { services and quality of service }\end{array}$ \\
& services & & \\
\hline
\end{tabular}


The research model in Figure 1 presents the four constructs hypothesized in this study and the nature of their expected relationship with VoIP adoption. The influential variables are defined are summarized in Table 2.

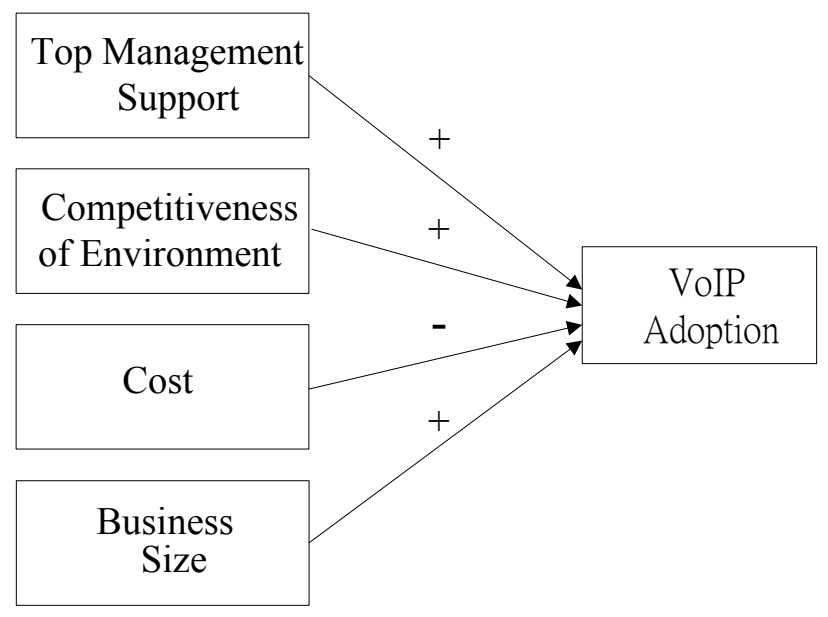

Figure 1 Antecedents of VoIP adoption

Table 2 Variables influencing the VoIP adoption

\begin{tabular}{cll}
\hline Variables & \multicolumn{1}{c}{ Definitions } & \multicolumn{1}{c}{ Sources } \\
\hline TOP1 & $\begin{array}{l}\text { VoIP increases the productivity of my } \\
\text { employees. }\end{array}$ & $\begin{array}{l}\text { Jeyaraj et al. (2006) and Premkumar and } \\
\text { Roberts (1999) }\end{array}$ \\
TOP2 & $\begin{array}{l}\text { My employees find VoIP easy to use. } \\
\text { I have seen what other companies } \\
\text { have achieved with VoIP. }\end{array}$ \\
ENV1 & $\begin{array}{l}\text { It is easy for our customers to switch Grandon \& Pearson (2004); Jeyaraj et al. } \\
\text { to another company for similar } \\
\text { products without much difficulty. }\end{array}$ \\
ENV2 & $\begin{array}{l}\text { The rivalry among companies in the } \\
\text { industry my company is operating in }\end{array}$ \\
is very intense. & $\begin{array}{l}\text { There are many products/services in } \\
\text { the market which are different from } \\
\text { ours but perform the same functions. } \\
\text { As I know, the competitors who have } \\
\text { adopted VoIP have gotten many } \\
\text { benefits. } \\
\text { The pressure of industry competitor } \\
\text { will influence the decision of adopting } \\
\text { VolP. }\end{array}$ \\
\hline
\end{tabular}


Table 2 Variables influencing the VoIP adoption (continued)

\begin{tabular}{cll}
\hline Variables & \multicolumn{1}{c}{ Definitions } & \multicolumn{1}{c}{ Sources } \\
\hline COST1 & $\begin{array}{l}\text { The costs of VoIP installation are far } \\
\text { greater than the benefits. }\end{array}$ & Premkumar \& Roberts (1999) \\
COST2 & $\begin{array}{l}\text { The cost of maintenance and support } \\
\text { of VoIP are very high for our } \\
\text { business. }\end{array}$ & \\
SIZE1 & $\begin{array}{l}\text { How many sale revenues in your } \\
\text { business in 2005 (USD)? }\end{array}$ & Patterson et al. (2003) \\
SIZE2 & $\begin{array}{l}\text { How many total employees in your } \\
\text { business ? }\end{array}$ & \\
\hline
\end{tabular}

Note: TOP1 TOP3 are top management support variables; ENV1 ENV5 are environment competitiveness variables; COST1 and COST2 are cost variables; SIZE1 and SIZE2 are business size variables.

\section{METHODOLOGY}

\section{Logistic regression approach}

Previous empirical and theoretical studies indicate that the adoption pattern of new technologies by business can be characterized fairly well in terms of the logistic regression (Hong \& Zhu, 2006; Mabert et al., 2006). Logistic regression is a popular statistical technique in which the probability of a dichotomous outcome (such as adoption or non-adoption) is related to a set of explanatory variables that are hypothesized to influence the outcome. It fits a special s-shaped curve, by taking the linear regression form, which could produce any $\mathrm{Y}$-value between minus infinity and plus infinity, and transforming it with the function (Salem et al., 2004).

$$
P=\frac{e^{Y}}{1+e^{Y}}
$$

which produces p-values between 0 (as $\mathrm{Y}$ approaches minus infinity) and 1 (as $\mathrm{Y}$ approaches plus infinity)?

For a logistic regression model, the maximum likelihood estimation (MLE) is used to estimate the unknown parameters (Fienberg, 1983). The MLE seeks to maximize the log likelihood which reflects how likely it is (the odds) that the observed value of the dependent variable may be predicted from the observed values of the independents. The reason for preferring to interpret the results of the logistic regression in terms of odds rather than probabilities is that odds is a pure summary statistic for the partial effect of a given predictor, controlling for the other predictors in the logistic regression (Demaris, 1992). 
The probability that VoIP adoption occurs given the test parameters $\mathrm{X} 1, \mathrm{X} 2, \ldots$, $\mathrm{Xn}$ is donated by

$$
\pi\left(X_{1}, X_{2}, \cdots, X_{n}\right)=P\left(Y \mid X_{1}, X_{2}, \cdots, X_{n}\right)=\frac{1}{\left[1+\exp \left(-\left(\beta_{0}+\sum_{i=1}^{n} \beta_{i} X_{i}\right)\right)\right]}
$$

where $\beta_{1}, \beta_{2}, \cdots, \beta_{n}$, are estimated by the MLE technique (Kleinbaum \& Kupper, 1978). To understand the interpretation of the logistic coefficient, the logistic model can be rewritten in terms of the odds of an event occurring, and represented by logit form of the model. To get the logit from the logistic model, a transformation of the model is made. The logit transformation, denoted as logit $\mathrm{P}(\mathrm{X})$, is given as follows:

$$
\operatorname{logit} P(X)=\ln \left(\frac{P(X)}{1-P(X)}\right)=\frac{1}{\left[1+\exp \left(-\beta_{0}+\sum_{i=1}^{n} \beta_{i} X_{i}\right)\right]}
$$

This transformation allows us to compute a number, called logit $\mathrm{P}(\mathrm{X})$, for each test case with input variables given by $\mathrm{X}$. The logistic regression model fits the log odds by a linear function of the variables (Lindgren, 1976).

$$
\operatorname{logit} P(X)=\beta_{0}+\sum_{i=1}^{n} \beta_{i} X_{i}
$$

A logistic regression model can be written in terms of the odds of an event occurring. These odds are defined as the ratio of the probability that an event will occur against the probability it will not. Rather the coefficients reflect the effect of individual explanatory variables on its $\log$ of odds $\ln [\mathrm{Pi} /(1-\mathrm{Pi})]$. The logistic regression of adoption is thus specified as a function as follows.

$$
\begin{aligned}
Y_{i}= & \beta_{0}+\beta_{1}(\text { TOP } 1)+\beta_{2}(\text { TOP } 2)+\beta_{3}(\text { TOP } 3)+\beta_{4}(E N V 1)+\beta_{5}(E N V 2) \\
& +\beta_{6}(E N V 3)+\beta_{7}(E N V 4)+\beta_{8}(E N V 5)+\beta_{9}(C O S T 1)+\beta_{10}(\text { COST } 1) \\
& +\beta_{11}(\text { SIZE } 1)+\beta_{12}(\text { SIZE } 2)+\varepsilon_{i}
\end{aligned}
$$

where $\mathrm{Yi}$ is the $\log$ odds of adoption for the ith observation and $\varepsilon \mathrm{i}$ is its error term.

\section{Predictive Validity and Misclassification Rate}

With regard to the case studies, the predictive validity is the capability of a model to predict the probability of a test case's outcome. A significant p-value and a chi-square statistic are applied to test the model fitness. This remove process is based upon the concept of hypothesis testing and falsification using statistical inference 
techniques (Preece, 1990). All variables were entered in the first step and the variable with the smallest partial correlation with the dependent variable was removed in the following step, based on removal criteria $(\mathrm{p}>0.05)$. The chi-square test fit goodness-of-fit compares the results of a study of data to determine how likely the sample results actually are, given the parameter estimates. A good model is one, which results in a high likelihood of the observed values or a small value for $-2 \mathrm{Log}$ Likelihiood (Hair et al., 1998)

For logistic regression models, which classify test cases as either test cases that adopt VoIP or test cases that do not adopt VoIP, two misclassification errors should be taken into consideration and examined. A type I error occurs when a test case that adopts VoIP is classified as a test case that does not adopt, while a type II error occurs when a test case that does not adopt VoIP is classified as a test case that adopts VoIP.

\section{Survey Procedures and Sample}

A detailed questionnaire that measures the various research variables was developed as follows. The items in the questionnaire were initially derived after an extensive literature review and were subjected to through scrutiny of the researchers. The data for the study were collected by postal mails from a large-scale field survey of 500 businesses in Taiwan, listed in the Top Directory of Top 500 Export-Import Business of Foreign Trade Bureau in Taiwan.1 We confirmed the company name by telephone to ensure that they could receive our academic research before mailing out the questionnaire. The questionnaire packages (included a letter explaining the study purpose, a pre-stamped return envelop, and a gift for appreciating subjects' participation) were mailed to the senior executives of the targeted enterprises.

\section{Measurement of Variables}

The dependent variable was measured using the question "Does company adopt VoIP?" (Yes/No) and thus, we can separate the samples into adopter and non-adopter. The independent variables were divided into four categories; three variables related to top management support, five variables related to environment competitiveness, and two variables related to installation cost, and two variables related to business size. The response items were given on a 5-point Likert scale where 1 is "strongly disagree" and 5 is "strongly agree"; showing the agreement degree of the aspects.

\footnotetext{
${ }^{1}$ http://www.trade.gov.tw
} 


\section{DATA ANALYSIS AND RESULTS}

The 500 mailing questionnaires were sent out in the first week of May 2006. By mid-June, 156 responses had been received for an overall response rate of $31.2 \%$. However, 6 responses were excluded because of incomplete responses. Compared to the previous studies (Rabinovich \& Evers, 2002; Tang, 2000), this response rate was concluded to be reasonable. Among the remaining 150 effective respondents, 105 had already implemented VoIP system and 45 businesses were non-adopter enterprises.

Table 3 Characteristics of the sample

\begin{tabular}{|c|c|c|c|c|}
\hline Rank of Enterprises & \multicolumn{2}{|c|}{ Number of samples } & \multicolumn{2}{|c|}{ Percentage } \\
\hline Top1 top100 & \multicolumn{2}{|c|}{30} & \multicolumn{2}{|c|}{20.0} \\
\hline Top101 top200 & \multicolumn{2}{|c|}{52} & \multicolumn{2}{|c|}{34.7} \\
\hline Top201 top300 & \multicolumn{2}{|c|}{41} & \multicolumn{2}{|r|}{27.3} \\
\hline Top301 top400 & \multicolumn{2}{|c|}{21} & \multicolumn{2}{|r|}{14.0} \\
\hline Top401 top500 & \multicolumn{2}{|c|}{6} & \multicolumn{2}{|r|}{4.0} \\
\hline Total & \multicolumn{2}{|c|}{150} & \multicolumn{2}{|c|}{100.0} \\
\hline Range of sales revenue (USD) & Adopter & Non-adopter & Total & Percentage \\
\hline Less than 100 million & 1 & 5 & 6 & 4 \\
\hline 100 500 million & 33 & 16 & 49 & 32.7 \\
\hline 500 2,000 million & 40 & 9 & 49 & 32.7 \\
\hline 2,000 million $\sim 5,000$ million & 20 & 9 & 29 & 19.3 \\
\hline Above 5,000 million & 11 & 6 & 17 & 11.4 \\
\hline Total & 105 & 45 & 150 & 100.0 \\
\hline Industry & Adopter & Non-adopter & Total & Percentage \\
\hline Electronic industry & 45 & 22 & 67 & 44.7 \\
\hline Optics instrument & 8 & 7 & 15 & 10.0 \\
\hline Metal and hardware & 12 & 2 & 14 & 9.3 \\
\hline Transport & 7 & 3 & 10 & 6.7 \\
\hline Plastic goods & 5 & 3 & 8 & 5.3 \\
\hline Chemical and pharmacy & 5 & 3 & 8 & 5.3 \\
\hline Food & 5 & 1 & 6 & 4.0 \\
\hline Textile & 3 & 2 & 5 & 3.3 \\
\hline Machinery & 3 & 1 & 4 & 2.7 \\
\hline leather & 1 & 0 & 1 & 0.7 \\
\hline Others & 11 & 1 & 12 & 8.0 \\
\hline Total & 105 & 45 & 150 & 100.0 \\
\hline Range of number of employee & Adopter & Non-adopter & Total & Percentage \\
\hline Less than 100 & 4 & 7 & 11 & 7.3 \\
\hline $100 \sim 400$ & 23 & 21 & 44 & 29.3 \\
\hline $400 \sim 1,000$ & 42 & 10 & 52 & 34.7 \\
\hline $1,000 \sim 2,500$ & 25 & 4 & 29 & 19.3 \\
\hline Above 2,500 & 11 & 3 & 14 & 9.3 \\
\hline Total & 105 & 45 & 150 & 100.0 \\
\hline
\end{tabular}


Data were processed by using the statistical package for the social science software (SPSS), English version 12.0. Descriptive information for the characteristics of the sample was summarized in Table 3. Most of the samples are listed between top 101 and top 200 Export-import Businesses, which accounted for 34.7\%. The top $201 \sim 300$, top $1 \sim 100$, top $301 \sim 400$ and top 401 500 accounted for $27.3 \%, 20.0 \%$, $14.0 \%$ and $4 \%$, respectively. The sales revenues of businesses in 2005 ranged from less than USD $\$ 100$ million to above USD $\$ 5,000$ million. Of these, $65.4 \%$ of businesses had sales revenue between USD $\$ 100$ million and $\$ 2,000$ million. The number of employee ranged from less than 100 to above 2,500. Of these, $34.7 \%$ businesses had employees from 400 to 1,000. Most respondents were in electronic industry which were main VoIP users. Overall, the sample represented a wide range of businesses, increasing the generalizability of the results.

Table 4 Results of logistic regression analysis

\begin{tabular}{ccccc}
\hline Variables & Coefficients & S.E. & Wald statistic & Significance \\
\hline Constant & -3.673 & 1.556 & 5.568 & $0.018^{* *}$ \\
TOP1 & 0.457 & 0.210 & 4.728 & $0.030^{* *}$ \\
ENV1 & 0.547 & 0.288 & 3.612 & $0.057^{*}$ \\
COST1 & -0.569 & 0.308 & 3.419 & $0.064^{*}$ \\
COST2 & -0.721 & 0.429 & 2.819 & $0.093^{*}$ \\
SIZE1 & 0.820 & 0.377 & 4.742 & $0.029^{* *}$ \\
\hline
\end{tabular}

Notes: $-2 \log$ likelihood $\chi^{2}=30.525$ (d.f. $=6$ )

** Significant at 0.05 level, * Significant at 0.1 level

S.E.: Standard error

In order to test the relative importance of the independent variables with regard to the adoption of VoIP, the model was analyzed using logistic regression analysis with the backward stepwise likelihood ratio method (Menard, 1995). The significance of the regression coefficients of the hypothesized independent variables was examined to determine support for the hypothesis. Wald statistics were used in the significance test. Smaller values of the $-2 \log$ likelihood measure indicated better model fit (Hair et al., 1998). Formal statistically (Wald Chi-squares) tests are available in logistic regression to test the significance of each model with the particular variable removed. At each step, the variable with the largest p-value is dropped. This process is repeated until there is no p-value that is greater than 0.10 , the significance level used for the chi-squared test (Zhang et al., 2003). The final results of the model are presented in Table 4. Five remaining variables (TOP1, ENV1, COST1, COST2 and SIZE1) are 
significant at the 0.1 level with the Chi-square value of 30.525 .

Our results partially confirm the proposed hypotheses. The coefficient of SIZE1 is the largest among the significant variables, implying sale revenue in business has a relatively important influence in the VoIP adoption. The larger the business is, the greater the resource it had. Therefore, its ability to bring in technical employees, purchase information equipments, and establish a communication network system was superior to that of small business. Small businesses are restricted by limited resources of capital and technical experts, so the adoption of VoIP represents as a disproportionately large financial risk. Only business that has adequate financial and organizational resources could consider VoIP adoption as a viable project to undertake.

In addition, top management support implies a positive attitude in the network construction. In general, it helps the successful implementation of different private branch exchange systems. As VoIP increases the productivity of the employees and hence top management has higher intention to use them. Competitiveness of environment is also an important influential factor to VoIP adoption. If their customer is easy to switch to another competing rival for similar services/products without much difficulty, the business will speed up the VoIP adoption plan to strengthen their competitive advantage. Further, in our study, cost was found to be negatively related to VoIP adoption. If telephony cost and human resource cost could not be reduced effectively after installing VoIP, the business would suspend VoIP adoption plan.

We next assess the discriminating power of the model. As shown in Table 5, the model correctly predicted 95 test cases (with the correct \% of 90.5) out of the 105 test cases that adopted VoIP. Only 10 test cases that adopt VoIP were predicted as test cases that did not adopt VoIP (type I error). The model also correctly predicted 19 test cases (with the correct \% of 42.2) out of 45 test cases that did not adopt VoIP. But 26 test cases that did not adopt VoIP were predicted as test cases that adopt VoIP by the model (type II error). Only a total of 36 test cases (type I and II errors) were produced by logistic model in this case study. The model overall classification accuracy was $76.0 \%$, which is considered as a high percentage and much better than by random choices. 
Table 5 Logistic regression procedure classification

\begin{tabular}{cccc}
\hline \multirow{2}{*}{ Observed } & \multicolumn{2}{c}{ Predicted } & $\begin{array}{c}\text { Correct } \\
\text { Percentage(\%) }\end{array}$ \\
\cline { 2 - 3 } & Non-adopter & Adopter & 42.2 \\
Non-adopter & 19 & 26 & 90.5 \\
Adopter & 10 & 95 & 76.0 \\
\hline Overall & 29 & 121 & \\
\hline
\end{tabular}

\section{DISCUSSION AND CONCLUSION}

The primary purpose of this study is to identify the important predicting variables that may be used to effectively measure the VoIP adoption probability of the top 500 export-import businesses in Taiwan. The research is empirically evaluated using the data from 150 effective samples, with 105 businesses of them have adopted VoIP and businesses in electronic industry as major users. A binary logistic regression analysis was performed to assess the accurate prediction of sample in one of two categories of outcome (VoIP adopter and VoIP non-adopter). Several important finding can be drawn from the research.

All of our present findings share some commonalities with previous literature. First, in the top management support factor, hypothesis 1 is partly supported. We find that VoIP can increase the productivity of the employees; the business will have higher intention to use them. This is consistent with Jeyaraj et al. (2006) findings that top management play a critical role at an organizational innovation adoption. Second, in the competitiveness of environment factor, hypothesis 2 is also partly supported. It means that competitiveness of environment is another important factor that stimulates the adoption speed in VoIP. If its customer is easy to switch to another company for similar products, the business will consider adopting cost-efficient VoIP to strengthen their competitive advantage. This finding is in accordance with Jeyaraj et al. (2006) which found pressure from business competitors will be an important factor in technology adoption. Third, the hypothesis 3 is fully supported. In our research, cost was found to be negatively related to VoIP adoption. When business invests a VoIP system, it will be sensitive to evaluate the implementation and maintenance cost with its corresponding budget. This finding also concurs with the results of the study by Premkumar \& Roberts (1999). Finally, hypothesis 4 is partly supported. The research has shown a positive relationship between business size and VoIP adoption. Large business that possesses adequate financial resources, maturity of information technology, information-knowledgeable employee and higher operational 
performance are more likely to adopt VoIP due to the scale of economy Thus, the more business size, the higher intention business has to adopt VoIP. This also is supported by Patterson et al. (2003).

In fact, VoIP based on with packet-switched technology has a cost advantage over traditional circuit-switched telephone. Abundant evidences have revealed that VoIP could increase organizational productivity, flexibility, and competitiveness (Seo, 2008). However, an initial investment is necessary to reconstruct telephone and network system when investing such an information system. In our research result, the positive association between top management support and VoIP adoption suggests that continued emphasis on decision maker to realize the advantage gained from VoIP installation may lead to greater adoption intention. At the same time, the finding with regard to the cost factors found that investment cost may be a substantial barrier to popularize the service of VoIP. Therefore, the telephone bill, deployment cost or other relative costs and the ratio of investment will be evaluated when enterprises plan to adopt VoIP. Contrast to small enterprises, large export-import enterprise may have higher telephone bill to communicate with oversea branches and customers and thus, would be more likely to adopt VoIP to obtain the economic efficiency. Furthermore, in order to maintain and increase their market shares, enterprises need to adopt information technology to improve productivity and reduce operation cost, especially in the competitive industry environment. We believe that high competitive environment may be a stimulator to encourage enterprise managers to aware the benefit of VoIP and then to adopt it. From a viewpoint of supply side, VoIP providers could gain a better understanding of potential customers from our research results. For example, larger export-import and electronic enterprises may be an important marketplace which enormous marketing resources should be put in.

The major contribution of this paper is to investigate the influential factors of the VoIP adoption in Taiwan's enterprises. From a practical perspective, this paper is the first one to survey the VoIP usage of top 500 export-import business in Taiwan. However, certain limitations of the study should be noted. Our study focuses on the organizational and environmental factors of VoIP adoption. There exists wide scope for survey enterprise's VoIP usage. In reality, the influential factors of single technology adoption within single organization may not be the same in information system research (Lucas \& Spitler, 1999; Yi \& Davis, 2001). Many researchers have found that information technology adoption is influenced by a combination of factors such as organization culture, technology maturity and security. Future research may use our empirical results and the above influential factors may be further considered in 
the VoIP adoption. This study focused on export-import enterprises in Taiwan. However, to our knowledge, other industry of enterprise VoIP investigation has not yet taken place. As resulted, our model could provide an initial starting point to develop more comprehensive and detailed analysis of VoIP adoption.

\section{ACKNOWLEDGEMENT}

The first author is appreciated for the financial support from National Science Council in Taiwan (the grant NSC 96-2415-H-006 -SS2). We would like to thank an anonymous referee of Contemporary Management Research for his/her constructive report and very useful suggestions. Responsibility for remaining errors is ours.

\section{REFERENCES}

Basu, V., Hartono, E., Lederer, A. L., \& Sethi, V. (2002). The impact of organizational commitment, senior management involvement, and team involvement on strategic information system planning. Information and Management, 39, 513-524.

Bradfort, M., \& Florin, J. (2003). Examining the role of innovation diffusion factors on the implementation success of enterprise resource planning systems. International Journal of Accounting Information Systems, 4, 205-225.

Camison-Zornoza, C., Lapiedra-Alcami, R., Segarra-Cipres, M., \& Boronat-Navarro, B. (2004). A meta-analysis of innovation and organization size. Organization Studies, 25(3), 331-361.

Cerpa , N., \& Verner, J. N. (1998). Case study: The effect of IS maturity on information systems strategic planning. Information \& Management, 34(4), 199-208.

Cragg, P., \& King, M. (1993). Small firm computing: Motivators and inhibits. MIS Quarterly, 17(1), 47-60.

Demaris, A. (1992). Logit Modeling: Practical Applications. London: International Educational and Professional Publisher.

Dewar, R. D., \& Dutton, J. E. (1986). The adoption of radical and incremental innovations: an empirical analysis. Management Science, 32(11), 1422-1433.

Fienberg, S. E. (1983). The Analysis of Cross-classified Categorical Data, Cambridge. MA: MIT Press.

Grandon, E. E., \& Pearson, J. M. (2004). Electronic commerce adoption: An empirical study of small and medium US business. Information \& Management, 42, 197-216. 
Grover, V., \& Goslar, M. D. (1993). The initiation, adoption, and implementation of telecommunications technologies in US organizations. Journal of Management Information Systems, 10(1). 141-160.

Hair, J. F., Anderson, R. E., Tatham, R.L., \& Black, W.C. (1998). Multivariate Data Analysis, 5th edition, Upper Saddle River. NJ: Prentice-Hall.

Hart, P. J., \& Saunders, C. S. (1998). Emerging electronic partnerships: Antecedents and dimensions of EDI use from the supplier's perspective. Journal of Management Systems, 14(4), 87-111.

Hong, W., \& Zhu, K. (2006). Migrating to Internet-based E-commerce: Factors affecting E-commerce adoption and migration at the firm level. Information \& Management, 43, 204-221.

Jeyaraj, A., Rottman, J. W., \& Lacity, M. C. (2006). A review of the predictors, linkages, and biases in IT innovation adoption research. Journal of Information Technology, 21, 1-23.

Lin, T. C. (1995). Organizational factor of impact IT efficiency in business. Information Review, 14(2), 59-84.

Lindgren, B. W. (1976). Statistical Theory ( $3^{\text {rd }}$ ed.). New York: Macmillan.

Lu, B. H., Bateman, R. J., \& Chen, K. (2006). RFID enable manufacturing: Fundamentals, methodology and applications. International Journal of Agile Systems and Management, 1(1), 73-92.

Lucas, H. C., \& Spitler, V. K. (1999). Technology use and performance: A field study of broker workstations. Decision Science, 30(2), 291-311.

Kleinbaum, D. G. \& Kupper, L. L. (1978). Applied Regression Analysis and Other Multivariable Methods, North Scituate. MA: Duxbury Press.

Know, T. H., \& Zmud, R. W. (1987). Unifying the fragmented models of information systems implementation. In: Boland, R. J., Hirschheim, R. A. (Eds.), In Critical Issues in Information Systems Research. New York: John Wiley.

Mabert, V. A., Soni, A., \& Venkataramanan, M. A. (2006). Model based interpretation of survey data: A case study of enterprise resource planning implementations. Mathematical and Computer Modeling, 44, 16-29.

March, L. T., \& Ngai, E. W. T. (2006). Predicting the organizational adoption of B2C E-commerce: An empirical study. Industrial Management and Data Systems, 106(8), 1133-1147.

Matta, V., \& Moberg, C. (2006). The development of a research agenda for RFID adoption and effectiveness in supply chains. Issues in Information Systems, 7(2), 246-251. 
Menard, S. (1995). Applied Logistic Regression Analysis. Beverly Hills and London: Sage Publications.

Mondragon, A. E. C., Lyons, A. C., Michaelides, Z., \& Kehoe, D. F. (2006). Automotive supply chain models and technologies: A review of some latest development. Journal of Enterprise Information Management, 19(5), 551-562.

Patterson, K. A., Grimm, C. M., \& Corsi, T. M. (2003). Adoption new technologies for supply chain management. Transportation Research Part E, 39, 95-121.

Preece, R. (1990). Development control studies: Scientific method and policy analysis. Town Planning Review, 61(1), 59-74.

Premkumar, G., \& Ramamurthy, K. (1995). The role of inter-organizational and organizational factors on the decision mode for adoption of inter-organizational systems. Decision Sciences, 26(3), 303-336.

Premkumar, G., Ramamurthy, K., \& Crum, M. R. (1997). Determinants of EDI adoption in the transportation industry. European Journal of Information Systems, 6(2), 107-121.

Premkumar, G., Ramamurthy, K., \& Nilakanta, S. (1994). Implementation of electronic data interchange: an innovation diffusion perspective. Journal of Management Information System, 11(2), 157-186.

Premkumar, G., \& Roberts, M. (1999). Adoption of new information technologies in rural small businesses. OMEGA, The International Journal of Management Science, 27, 467-484.

Quaddus, M., \& Xu, J. (2005). Adoption and diffusion of knowledge management systems: Field studies of factors and variables. Knowledge-Based System, 18, 107-115.

Rabinovich, E., \& Evers, P. T. (2002). Enterprise-wide adoption patterns of inventory management practices and information systems. Transportation Research Part E, 38, 389-404.

Rogers, E. M. (1983). Diffusion of Innovation ( $3^{\text {rd }}$ ed.). New York: The Free Press.

Salem, A. M., Rekab, K., \& Whittaker, J. A. (2004). Prediction of software failure through logistic regression. Information and Software Technology, 46, 781-789.

Seo, S. (2008). VOIP-telephone service: Economic efficiencies and policy implications. Telematics and Informatics, 25, 47-55.

Shin, D. H. (2006). VoIP: A debate over information service or telephone application in US: a new perspective in convergence era. Telematics and Informatics, 23, 57-73. 
Steinbart, P. J., \& Nath, R. (1992). Problems and issues in the management of international data communications networks: The experience of American companies. MIS Quarterly, 16(1), 55-76.

Swanson, E. B. (1994). Information systems innovation among organizations. Management Science, 40(9), 1069-1092.

Tang, S. H. (2000). An impact factor model of Intranet adoption: An exploratory and empirical research. The Journal of Systems and Software, 51, 157-173.

Tobin, P. K. J., \& Bidoli, M. (2006). Factors affecting the adoption of voice Internet protocol (VoIP) and other converged IP service in South Africa. South Africa Journal Business Management, 37(1), 31-40.

Tornatzky, L. G., \& Klein, K. J. (1982). Innovation characteristics and innovation adoption-implementation: A meta analysis of findings. IEEE Transactions on Engineering Management, 29(11), 28-45.

Tsai, M. J. (2006). VoiceXML dialog system of the multimodal IP-telephony- the application for voice ordering service. Expert Systems with Applications, 31(4), 684-696.

Wieder, S. (2006). VoIP's impact on speech recognition. Speech Technology Magazine. Retrieved March 2010, from http://www.speechtechmag.com/Articles /?ArticleID $=29429$

Yi, M. Y., \& Davis, F. D. (2001). Improving computer training effectiveness for decision technologies: Behavior modeling and retention enhancement. Decision Science, 32(3), 521-544.

Zhang, G. P., Keil, M., Ril, A., \& Mann, J. (2003). Predicting information technology project escalation: a neural network approach. European Journal of Operational Research, 146, 115-120.

Zhang, Z., Lee, M., Huang, P., Zhang, L., \& Huang, X. (2005). A framework of ERP systems implementation success in China: An empirical study. International Journal of Production Economics, 98, 56-80. 